\title{
Characterization of surface water isotope spatial patterns of Scotland
}

\author{
Christian Birkel ${ }^{\mathrm{a}, \mathrm{b}, *}$, Rachel Helliwell ${ }^{\mathrm{c}}$, Barry Thornton ${ }^{\mathrm{c}}$, Sheila Gibbs ${ }^{\mathrm{c}}$, Pat Cooper ${ }^{\mathrm{c}}$, \\ Chris Soulsby ${ }^{\mathrm{b}}$, Doerthe Tetzlaff ${ }^{\mathrm{b}}$, Luigi Spezia ${ }^{\mathrm{d}}$, Germain Esquivel-Hernández ${ }^{\mathrm{e}}$, \\ Ricardo Sánchez-Murillo ${ }^{\mathrm{e}}$, Andrew J. Midwood ${ }^{\mathrm{c}, \mathrm{f}}$

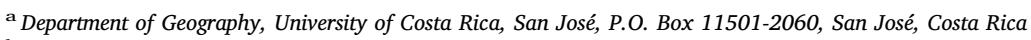 \\ ${ }^{\mathrm{b}}$ Northern Rivers Institute, University of Aberdeen, Aberdeen AB24 3UF, Scotland, United Kingdom of Great Britain and Northern Ireland \\ ${ }^{\mathrm{c}}$ The James Hutton Institute, Aberdeen AB15 8QH, Scotland, United Kingdom of Great Britain and Northern Ireland \\ d Biomathematics and Statistics Scotland, Aberdeen AB15 8QH, Scotland, United Kingdom of Great Britain and Northern Ireland \\ e Stable Isotope Research Group, National University of Costa Rica, Heredia, Costa Rica \\ ${ }^{\mathrm{f}}$ Department of Biology, University of British Columbia - Okanagan, Kelowna V1V 1V7, B.C., Canada
}

\section{A R T I C L E I N F O}

\section{Keywords:}

Scotland

Stable isotopes

Isoscapes

$d$-Excess

Geographically weighted regression models

\begin{abstract}
A B S T R A C T
The extended National Waters Inventory of Scotland (NWIS) monitoring network in combination with an extensive, supplementary low flow sampling campaign was used to create isoscapes of surface water for management purposes at high spatial resolution (100 m grid) across Scotland. The $\delta^{2} \mathrm{H}$ isoscape shows a strong isotopic separation along a north-south and east-west topographic (mountainous to the north and west and lowlands to the east) and climatic (wetter west, drier east) gradients. Isotopes were enriched in the western domain and depleted in the east and central Highland domains. The surface water $d$-excess isoscape show more complex spatial variability mainly related to contrasting moisture sources (sub-tropical North Atlantic Ocean, the North Sea, Polar Continental, and the Arctic) as well as secondary evaporation processes. The two-year NWIS isotope record exhibited a significant seasonal evaporative effect on surface water isotopes that progresses from winter through to a maximum in autumn as indicated by Local Evaporation Lines (LELs). The surface water isoscapes can be efficiently reproduced with geographically weighted regression (GWR) models using gridded annual precipitation, remotely sensed actual evapotranspiration, land cover, soil wetness, catchment area, and mean elevation. The GWR models showed potential to assess isotopic changes under future climate and land use change.
\end{abstract}

\section{Introduction}

The concept of "isotopic landscapes" or "isoscapes" (West et al., 2010) has become a valuable tool to understand hydro-climatic processes and their effect on water resources across different spatial scales (Bowen and Revenaugh, 2003; Terzer et al., 2013; Jasechko et al., 2013; Evaristo et al., 2015; Good et al., 2015). Historically, the use of stable water isotopes in the environmental sciences was dependent on analytical capability. Fortunately, the development of inexpensive instrumentation based on laser spectroscopy has greatly enhanced our ability to characterise the temporal and spatial variability of isoscapes at high resolution (Gupta et al., 2009; Good et al., 2014; Munksgaard et al., 2014). Recently, isoscapes have emerged as a low-cost and effective tracer visualization technique to understand precipitation dynamics (Lachniet and Paterson, 2009; Sánchez-Murillo et al., 2016a, 2016b), groundwater recharge mechanisms (Heilweil et al., 2009;
Jasechko and Taylor, 2015; Sánchez-Murillo et al., 2016a, 2016b), paleoclimate (Vimeux et al., 2005; Lachniet, 2009; Risi et al., 2010), and ultimately, enhance water resources management (Bowen and Good, 2015). However, to use isoscapes as a physically-based management tool - as advocated by Bowen and Good (2015) - the spatial resolution needs to cover regional as well as local scales. The latter requires sampling efforts able to generate a complete spatial representation of complex terrain. A sufficiently high density of observations is particularly important in mountainous landscapes due to the complex interaction of hydro-meteorological processes and small scale landscape heterogeneity (Yamanaka et al., 2015).

In addition to characterising spatial variation with the highest possible density monitoring network, the geostatistical method used for spatial interpolation is also critical. There are several algorithms available and all have advantages or disadvantages, but there is little guidance as to which algorithm is the most suitable for isoscape

\footnotetext{
* Corresponding author at: Department of Geography, University of Costa Rica, San José, P.O. Box 11501-2060, San José, Costa Rica.

E-mail address: christian.birkel@ucr.ac.cr (C. Birkel).
} 
applications. Common approaches use a) relatively simple nearest neighbour-related interpolations (such as spline and inverse distance weighting) or b) linear regression, taking explanatory variables such as elevation, latitude, distance to the ocean, slope, and stream network into account (Bowen and Revenaugh, 2003; Wassenaar et al., 2009; Kaseke et al., 2016). Newer network-related algorithms, tailored to take, for example, stream networks into account are also available (Bowen et al., 2011). However, few isotope studies look to incorporate the most basic features of spatial heterogeneity for interpolation. The class of "geographically weighted regression" (Fotheringham et al., 2002) explicitly allows a comprehensive assessment of different explanatory variables that are potentially related to isotopes, their spatial patterns and the physical processes governing water isotope fractionation.

Oxygen-18 $\left(\delta^{18} \mathrm{O}\right)$ or deuterium $\left(\delta^{2} \mathrm{H}\right)$ isoscapes have been used as a potential indicator to explain moisture origin and evaporative fractionation processes which lead to observed isoscapes and their potential practical application to water management (Sánchez-Murillo et al., 2016a, 2016b). More recently, isotopes are increasingly analysed together with the deuterium excess ( $d$-excess $=\delta^{2} \mathrm{H}-8 \cdot \delta^{18} \mathrm{O}$; originally proposed by Dansgaard, 1964). The $d$-excess is the y-intercept of the global meteoric water regression line (GMWL) with a value of $+10 \%$. If the $d$-excess departs from $+10 \%$, particularly for lower values, this is a potential indication of land surface evaporation that affects the isotopic composition. Jouzel et al. (2013) mentions that precipitation $d$ excess values may deviate from $+10 \%$ due to a combination of three factors: a) a relative humidity $(\mathrm{RH})$ increase in the precipitation source, b) a decrease in sea surface temperature (SST), and c) greater wind speeds $\left(>7 \mathrm{~ms}^{-1}\right.$ ) affecting the evaporation regime and subsequent kinetic fractionation. Furthermore, the recycling of transpiration fluxes, which could represent up to $80-90 \%$ of terrestrial evapotranspiration (Jasechko et al., 2013), may affect the parental isotope composition of precipitation. Such changes, may in combination with catchment specific characteristics, ultimately affect surface water isotopes. Similarly, indices such as the $l c$-excess based on the deviation from the Local Meteoric Water Line (LMWL) rather than the GMWL proved a useful indicator of evaporative fractionation mainly at smaller catchment scales (Sprenger et al., 2016). Therefore, the composition of stable isotopes in combination with derivatives such as the $d$-excess can be powerful tools to explain spatial variation of the components of the hydrological cycle (e.g. precipitation, evapotranspiration and surface waters) and any deviation from the observed and interpolated average conditions caused by environmental changes including climate and land use changes.

Isoscapes and their physical drivers are particularly useful in areas with marked precipitation, temperature and topographical gradients. Scotland represents a heterogeneous environment and we, therefore, build on previous work by Darling and Talbot (2003) and Tyler et al. (2016) who first constructed precipitation isoscapes for the British Isles. In this study, we focus on surface water isotope data and analyse spatial variability at a national (Scottish) scale, interpolated to relatively high spatial resolution ( $100 \mathrm{~m}$ grid), to inform management decisions from regional to local scale. Inferences on moisture sources covering Scotland could be made from surface water isotopes, even in absence of precipitation isotope records, providing that catchment characteristics are accounted for. To relate isoscapes to environmental characteristics as explanatory variables of their average spatial variability, we constructed geographically weighted regression (GWR) models. The GWR models can capture such spatial heterogeneity explaining important drivers on surface water isoscapes and can serve as a learning tool for potential future isotopic changes driven by environmental (climate and land use) change.

The specific objectives were:

a) To analyse and complement the National Waters Inventory of Scotland (NWIS) stable isotope data base for spatial patterns using regression and interpolation techniques.

b) To relate the surface water isotopes to environmental variables to identify important drivers of spatial patterns using GWR models across Scotland.

c) To evaluate GWR models for construction of surface water isoscapes and the relationship to precipitation source moisture.

\section{Background, monitoring and methods}

\subsection{Site description and precipitation, surface water and groundwater monitoring}

Surface water sites (rivers) for stable water isotope analysis (number of sites $(\mathrm{n})=90$ ) across Scotland were sampled at approximately monthly intervals using a standard protocol for two years from 2011 to 2013. The monitoring sites were mostly established as part of the National Water Inventory for Scotland project (NWIS) to systematically assess the environmental state of Scottish water bodies as required by the European Union Water Framework Directive (Dawson et al., 2012). The sites corresponded to the Harmonised Monitoring Scheme (HMS Ferrier et al., 2001) that is managed by the Scottish Environmental Protection Agency (SEPA) (Fig. 1A-C) and was recently used by Spezia et al. (2017) for water quality classification. The NWIS sites were complemented with research sites of at least monthly sampling from the University of Aberdeen to improve spatial coverage ( $n=14$; Soulsby et al., 2014, 2015). The monitoring network covers catchments from $<1 \mathrm{~km}^{2}$ to the largest Scottish catchment (River Tay) with $\sim 4900 \mathrm{~km}^{2}$ (Table S1). The sites also span a wide range of elevations (from lowlands to highlands with a maximum altitude of $\sim 1300 \mathrm{~m}$ a.s.1.) (Fig. 1A), land uses (intense agriculture, forested, urban, and heather moorland), and the observed marked west-east Scottish climate gradient (high rainfall up to $\sim 3 \mathrm{myr}^{-1}$ in the west compared to the much drier east coast with annual rainfall of $\sim 800 \mathrm{~mm} \mathrm{yr}^{-1}$ ) (Fig. 1B) (Birkel et al., 2013). Air temperature (mean annual temperature across Scotland, MAT $=6.3^{\circ} \mathrm{C}$ ) decreases with altitude in correspondence to an environmental lapse rate of close to $-0.6{ }^{\circ} \mathrm{C} / 100 \mathrm{~m}$ (Fig. 1C) and the southwest is milder compared to a cooler east. Soils range from intensively farmed brown earth soils along the east coast to podzolic soils over much of the Highlands with less developed inceptisols on the steeper hillslopes. The valley bottoms and hilltop areas are frequently dominated by organic rich histosols. The soil cover importantly affects recharge and runoff generation processes across Scotland (Soulsby et al., 2006).

In addition, 29 groundwater wells were monitored over the same period, but sites are concentrated on the east coast and are located mostly within Scottish Monitored Priority Catchments identified as Nitrate Vulnerable Zones (NVZ). The wells cover a range of depths from $10 \mathrm{~m}$ to $50 \mathrm{~m}$ of mostly sedimentary rocks (old red sandstone), glacial (till, sand, and gravel), and alluvial (sand, gravel) deposits. As a reference, we included data from five precipitation monitoring sites compiled from the published literature concentrated on the east coast and the highlands (Soulsby et al., 2014, 2015). Apart from the hightemporal resolution (daily) and localised precipitation data collected by Soulsby et al. (2014, 2015), the coverage of precipitation isotope information over the whole of Scotland, is scarce for the period 2011-2013 and only one historic Global Network of Isotopes in Precipitation (GNIP) station existed with data for 1965 (Eskdalemuir). Due to insufficient NWIS sample coverage in the west of Scotland and the northern (Shetlands, Orkneys) and western islands (Inner and Outer Hebrides), we conducted an additional surface water spot sampling campaign $(n=56)$ under low flow conditions to eliminate the effect of high flow events with more depleted or enriched isotopes over spring and early summer 2016. The complete data set of surface water samples ( $n=146$ ) was used to construct isoscapes and to assess spatial patterns. Only the 90 longer-term sites with monthly sampling from 2011 to 2013 were used for temporal pattern analysis. All samples were 
A

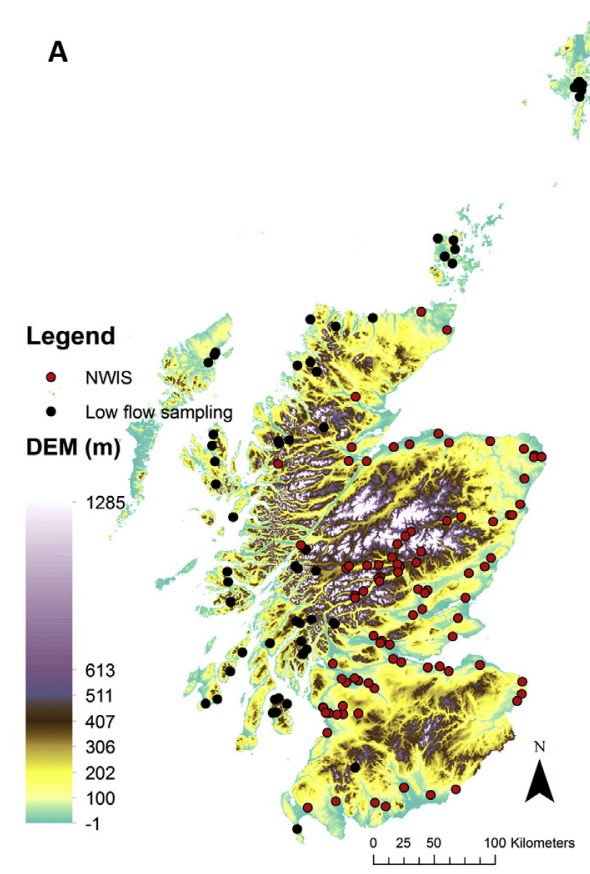

B
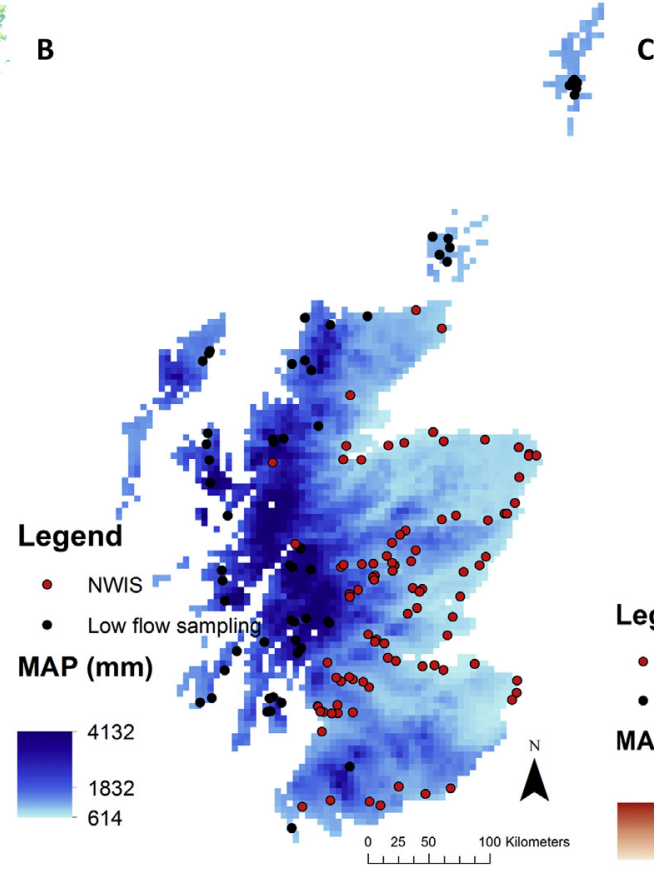

C

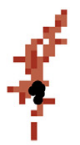

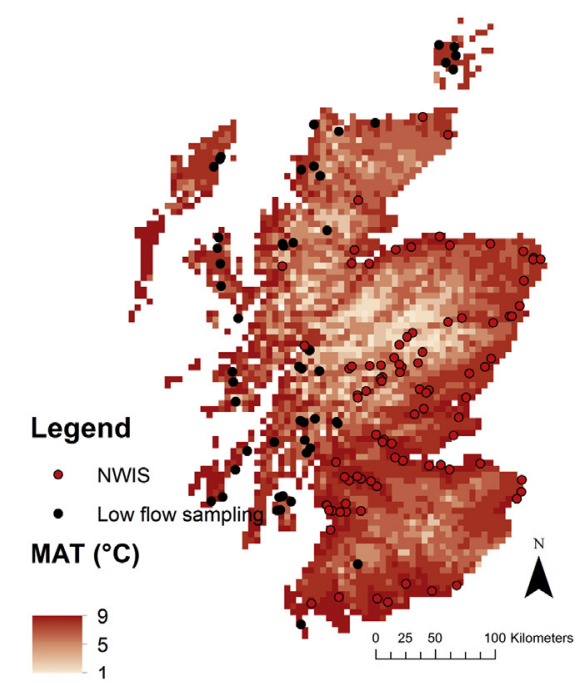

Fig. 1. Scottish map of A) the topographical gradient using the SRTM $30 \mathrm{~m}$ digital elevation model (DEM), B) the 1982-2010 mean annual precipitation (MAP in $\mathrm{mm}$ ) with the complete surface water stable isotope monitoring (NWIS and low flow spot sampling) and C) the 1971-2000 mean annual temperature (MAT in ${ }^{\circ} \mathrm{C}$ ).

analysed either at the isotope laboratories of the James Hutton Institute (JHI) in Aberdeen and at the Northern Rivers Institute at the University of Aberdeen using a Los Gatos DLT-100 laser analyser with a precision of $0.6 \%$ for $\delta^{2} \mathrm{H}$ and $0.1 \%$ for $\delta^{18} \mathrm{O}$ using an International Atomic Energy Agency (IAEA) analytical protocol (Newman et al., 2009) to correct for drift. Stable isotopes are reported in the delta-notation (\%oper mil) using Vienna Standard Mean Ocean Water (VSMOW) reference standards for calibration.

\subsection{Environmental characteristics of Scotland}

We combined the isotope data with a compilation of a Scottish-wide database of environmental variables to identify relationships and drivers of spatiotemporal isotope patterns. Long-term mean annual precipitation (MAP, $\mathrm{mm} \mathrm{yr}^{-1}$ ) from 1982-2010 visualized in Fig. 1B was compiled by the Meteorological Office with a $5-\mathrm{km}$ grid size (Met Office, 2016). Mean annual actual evapotranspiration (AET, $\mathrm{mm} \mathrm{yr}^{-1}$ ) was derived from monthly MODIS (Moderate Resolution Imaging Spectroradiometer) products for the period from 2000 to 2014 (Zhang et al., 2009) and the final MODIS product was converted into $\mathrm{mm} \mathrm{yr}^{-1}$. We calculated annual hydro-climatic indices, such as the AET to MAP ratio (water availability). The mean annual runoff (MAR, $\mathrm{mm} \mathrm{yr}^{-1}$ ) was calculated using a simple water balance difference (MAP-AET) assuming negligible storage variations and was used to calculate the runoff coefficient (MAR/MAP) for analysis. Furthermore, we compiled land use data from the last survey in 2007 (LCM07) using the following land use classes in grid format: forest, urban, agriculture, and moorland. Soil data was derived from the UK HOST (Hydrology of Soil Type classification) database (Boorman et al., 1995). Specifically, we used the HOST derived catchment average Standard Percentage Runoff (SPR) index in \%, which is the percentage of rainfall that contributes to the increase of overland flow. Geological information was provided by the UK geological service (British Geological Society, 2016). The topography in Fig. 1A was derived from the global $30 \mathrm{~m}$ SRTM (Shuttle Radar Topography Mission) elevation product. The resulting digital elevation model for Scotland was used to derive parameters such as the corresponding catchment area of the monitored sites, median elevation, slope, and aspect.

\subsection{Statistical models to explain isotope patterns}

The complete spatial and temporal gridded dataset was analysed using linear and GWR models and a simple spline interpolation to construct the surface water isoscapes. The GWR models were used to assess important drivers on the spatial distribution of surface water isotopes. Simple linear regression was used to construct Local Evaporation Lines (LELs) for surface water isotopes $\left(\delta^{2} \mathrm{H}\right.$ and $\left.\delta^{18} \mathrm{O}\right)$. The LELs were compared to precipitation and groundwater isotopic compositions to assess seasonality and secondary evaporative fractionation effects. The regression linearly relates $\delta^{2} \mathrm{H}=\mathrm{m} \cdot \delta^{18} \mathrm{O}+\mathrm{y}$, with $m$ being the slope and $y$ the $d$-excess in \%o. The $\delta^{2} \mathrm{H}$ and $d$-excess data was not transformed prior to analysis, which was supported by final residual diagnostics. Isotopic similarity was assessed using k-means cluster analysis. The significant number of clusters was identified at the $95 \%$ significance level using bootstrap resampling.

All raster isoscapes were derived using a $100-\mathrm{m}$ grid resolution. These initial interpolations were performed in ArcGIS 10.3 (ESRI, USA) based on a thin plate spline algorithm (Franke, 1982). Additionally, we used GWR to construct regression models able to represent the spatial heterogeneity of surface water isotopes based on spatially distributed explanatory environmental variables from the complete gridded database (Fotheringham et al., 2002) as simple static regression models did show poor performance. GWR was chosen over other possible methods (e.g. Generalized Additive Models) for assessment of spatial heterogeneity and the potential to find physically meaningful models for surface water isotopes (Brunsdon et al., 1996). GWR is a simple local regression model where:

$y_{i}=\beta_{i 0}+\sum_{k=1}^{m} \beta_{i k} x_{i k}+\varepsilon_{i}$

with $y$ being the predicted (dependent) variable (in our case the stable isotope of $\delta^{2} \mathrm{H}$ and $d$-excess at monitoring location $i$ ), $\beta_{i o}$ the intercept parameter at location $i, m$ is the number of independent variables, $\beta_{i k}$ the local regression coefficient for the $k^{\text {th }}$ independent variable at location $i, x_{i k}$ the $k^{\text {th }}$ explanatory (independent) variable at location $i$ and the random error term $\varepsilon_{i}$. However, in GWR the coefficients $\beta_{i k}(\mathrm{k}=0$, $\ldots, \mathrm{m})$ are allowed to vary spatially and a gridded spatial map for each 
coefficient can be calculated. The spatial variability is achieved by providing a local model for each variable through fitting a regression equation to every feature falling within the bandwidth of each target feature. The shape and extent of the bandwidth is dependent on the number of neighbours selected using the corrected Akaike Information Criterion (AICc) (Hurvich and Tsai, 1993) of an adaptive kernel. The optimal bandwidth is found through minimizing the AICc (Eq. (4)), which penalizes model fits using smaller bandwidths which represent more complexity compared to larger bandwidths. Parameter estimates and predicted values for GWR are computed using the locally fitted exponential spatial weighting function $w_{i j}$ with $d_{i j}$ being the distance between observation $i$ and $j$ and $b$ the bandwidth. The weights will be at a maximum of 1 for an observation at a GWR calibration point and decrease according to an exponential curve with increasing distance between observation and calibration point:

$\omega_{i j}=\exp \left(-\frac{d_{i j}}{b}\right)$

The best-performing and most parsimonious local models from all possible model combinations were selected according to the adjusted coefficient of determination $\mathrm{R}^{2}\left(\operatorname{adj} \mathrm{R}^{2}\right)$ and the AICc:

$\operatorname{adj} R^{2}=1-\left(\frac{n-1}{n-p-1}\right)\left(1-R^{2}\right)$

$A I C c=A I C+2 p \frac{(p+1)}{n-p-1}$

where $R^{2}$ is the coefficient of determination, $n$ is the number of observations and $p$ is the number of independent variables. Furthermore, all regression models were checked for co-linearity using the Variance Inflation Factor (VIF) with VIF > 7.5 leading to rejection of models.

$V I F=\frac{1}{1-R^{2}}$

\section{Results}

\subsection{Isotope characteristics of different water sources in Scotland}

Important differences in the isotopes were observed between water sources (Tables 1 and S1). Generally, precipitation isotopes showed the greatest temporal variability (typically from around -160 to close to $0 \%$ for $\delta^{2} \mathrm{H}$ ) as indicated by the standard deviation of continuous records, followed by surface water isotopes (from around -80 to $-40 \%$ o for $\delta^{2} \mathrm{H}$ ), and the smoothed groundwater isotopes (from around -70 to $-55 \%$ for $\delta^{2} \mathrm{H}$ ). This order in variability was mainly related to catchment specific mixing processes that modify and damp the isotopes as they progress through the landscape. On the other hand, the number of observations dominated the spatial variability. Mean surface water isotopes across all sampling sites showed the largest range from $-20 \%$ to $-59 \%$ for $\delta^{2} \mathrm{H},-4 \%$ to $-9 \%$ for $\delta^{18} \mathrm{O}$, and a $d$-excess from close to $4 \%$ to almost $18 \%$ (Fig. 2A) compared to spatially limited (east coast) sampling of groundwater and precipitation isotopes. Spatially, surface water in the west showed greater enrichment and samples were more depleted in the east (Fig. 3A). Generally, the water balance for Scotland consisted of a mean annual precipitation (MAP) of $1403 \mathrm{~mm}, 475 \mathrm{~mm}$ of actual evapotranspiration (AET), and $929 \mathrm{~mm}$ of annual runoff (MAR). A relatively low spatial variability of AET $(\mathrm{SD}=71 \mathrm{~mm})$ is associated with limited solar energy in Scotland compared to larger spatial variabilities of MAP $(\mathrm{SD}=313 \mathrm{~mm})$ and MAR $(\mathrm{SD}=332)$ (Tables 1 \& S1). Such relatively low AET values across Scotland might also imply limited capacity for fractionation affecting surface waters.

\subsection{Seasonal differences in surface water isotopes}

Seasonal LEL analysis of the NWIS isotope record indicates a
Table 1

Overall summary statistics of all isotope monitoring sites and variables in terms of spatial variability (standard deviation - st. dev.). The $100 \mathrm{~m}$ pixel long-term water balance components in $\mathrm{mm}$ are also shown. The mean annual precipitation (MAP) was derived from Met Office records for the period 1982-2010, the mean annual actual evapotranspiration (AET) was taken from MODIS (2000-2015) and the calculated discharge (Q) assumes negligible storage changes and was calculated using a simple water balance difference (MAPAET).

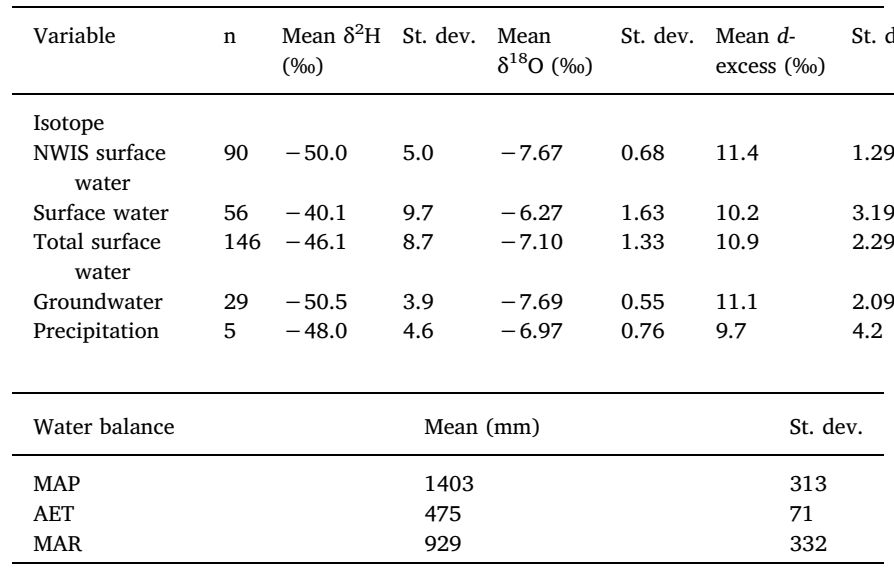

progressive fractionation effect from winter through to a maximum in autumn (Fig. 2B). A significant change in slope of the regression lines (from 6.9 in winter to 5.1 in autumn, significant at $\mathrm{p}<0.05$ ) compared to the GMWL, reflects the impact of surface waters being derived from sources exposed to greater evaporation rates from spring to late summer (Fig. 2B).

\subsection{Surface water isoscapes}

We constructed mean surface water $\delta^{2} \mathrm{H}\left(\delta^{18} \mathrm{O}\right.$ shows identical patterns and were not visualized here) and $d$-excess isoscapes using a simple spline interpolation algorithm (Fig. $3 \mathrm{~A}$ and B). The $\delta^{2} \mathrm{H}$ isoscape showed a strong isotopic separation of more enriched surface waters across the west domain (from north to south) (by around -9 to $-20 \% 0$ for $\delta^{2} \mathrm{H}$ ), while the eastern domain and the central highlands of Scotland are significantly more depleted (by around -30 to $-50 \%$ for $\left.\delta^{2} \mathrm{H}\right)$. Exceptions were apparent in the north-eastern domain and further inland to the south and westerly areas with more enriched surface waters. Such an isotopic separation is most likely a product of the variable influence of polar and sub-tropical maritime air masses, coupled with the presence of substantial orographic barriers (Central Highlands of Scotland with elevations $>1000 \mathrm{~m}$ asl). The spatial isotope patterns were further supported by cluster analysis (Fig. 4), which resulted in three statistically significant clusters. The cluster 1 is spatially and isotopically bracketed by the more depleted cluster 2 and the most enriched cluster 3 representing the northern and western islands and the west coast (Fig. 4B). These patterns support the source humidity from westerlies and the North Sea as well as rain out of heavier isotopes over the Central Highlands reflected in surface water isotopes.

The $d$-excess isoscape exhibited a more complex spatial pattern with values above $+10 \%$ (blue colour in Fig. $3 \mathrm{~B}$ ) mainly located in a small band along the east coast, the Central Highlands breaking through to the northern west coast and a smaller band located in the south west of Scotland. The latter zones were likely influenced by an enhanced recycling of continental moisture (sub-tropical continental and polar continental air mass sources). Most of the west coast and islands showed $d$-excess values below $+10 \%$ indicating distinctive moisture sources (sub-tropical north Atlantic westerlies) as well as an increasing influence of evaporative fractionation of surface waters possibly due to saturated peaty soils and standing waters (Fig. S1). There was also a 

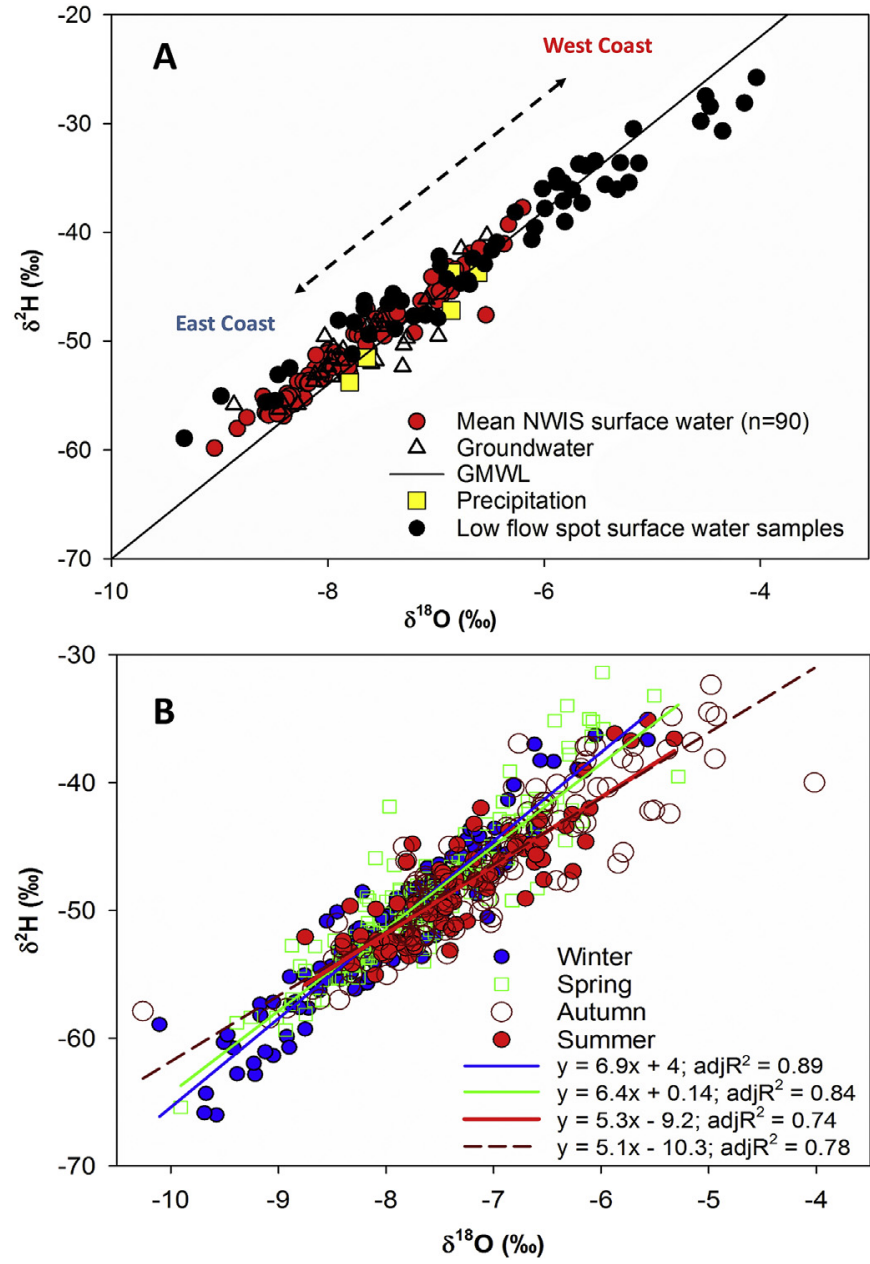

Fig. 2. A) The mean NWIS and low flow spot sampling stable isotope composition of all sites $(n=146)$ and types of waters (mean annual SW, GW, and amount-weighted P) are plotted against the Global Meteoric Water Line (GMWL). B) The NWIS surface water isotope samples $(n=90)$ were separated according to season with constructed Local Evaporation Regression Lines (LELs) showing progressive influence of secondary evaporative effects from a minimum in winter through to the maximum in autumn as indicated by the decreasing slope of the LELs. Precipitation and groundwater sampling did not show any similar fractionation effects.

band of $d$-excess below $+10 \%$ across the northeast and south of Scotland (Fig. 3B) likely related to increased groundwater influence and environmental variables such as saturated soils and presence of lochs that actively contribute fractionated surface water to streams.

\subsection{Predictability of surface water isoscapes and important drivers}

In an attempt to predict the surface water isoscapes and to identify the most important environmental drivers, we constructed GWR models of surface water $\delta^{2} \mathrm{H}$ (Fig. 5A, B) and $d$-excess (Fig. 6, Table 2). Fig. 5A shows the predicted $\delta^{2} \mathrm{H}$ superimposed over the reclassified spline interpolated isoscape from Fig. 3A for direct comparison. The local $\mathrm{R}^{2}$ model performance can be observed in Fig. 5B. Generally, the GWR model was able to reproduce the previously observed isotopic separation of surface water $\delta^{2} \mathrm{H}$ with particularly low residuals on the west coast, east coast, and the Central Highlands. The latter was also reflected in the best model performance values up to $R^{2}$ values of 0.66 (Fig. 5B). The model performed less well over south-western Scotland $\left(R^{2}\right.$ values $\left.<0.3\right)$. The best-fit models are shown in Table 2 and were selected based on the minimum AICc and maximum adj $\mathrm{R}^{2}$ values. The selected best-fit GWR model of surface water $\delta^{2} \mathrm{H}$ used catchment area, forest and SPR, and elevation as the most important explanatory variables. Interestingly, hydro-climatic variables were not selected as important by the GWR model procedure indicating an increased influence of catchment characteristics on surface water isotopes.

The selected best-fit and most parsimonious 4 parameter GWR model of $d$-excess used the AET/MAP index, catchment area, urban cover, and elevation as the most important explanatory variables. Most features could be reproduced with the GWR $d$-excess model, particularly for the low $d$-excess values coupled to the most enriched samples (Fig. S1) dominating the west coast of Scotland (Fig. 6A). The model performance progressively decreased from the west towards the depleted and greater $d$-excess values at the east coast. Generally, the $d$ excess GWR model performance $\left(\operatorname{adjR}^{2}=0.36\right)$ was well below the $\delta^{2} \mathrm{H}$ model (Fig. 6B).

\section{Discussion}

\subsection{Climate influences on surface water stable isotopes in Scotland}

Isoscapes have been used as a management tool to assess hydrological processes such as evaporation (Gat et al., 1994), to estimate transpiration (Jasechko et al., 2013), mixing of soil waters (Good et al., 2015), and groundwater recharge processes (Sanchez-Murillo and Birkel, 2016). However, increased sampling efforts are needed to gain a more complete spatial picture of isotope patterns. The surface water sampling sites represent, in almost all cases, the most downstream river location and the isotope samples represent an averaging of runoff generation processes across different catchment areas that, in total, cover up to $85 \%$ of the whole territory of Scotland. To enhance the spatial representation of the precipitation isotope records located on the east coast and the central highlands of Scotland (Soulsby et al., 2014, 2015), data were compared to the annual and monthly global precipitation isoscapes by Bowen and Revenaugh (2003). A significant mismatch ( $>-5 \%$ for $\delta^{2} \mathrm{H}$ on grid cells with observations) was observed. The reason might be that the regression model used by Bowen and Revenaugh (2003) for spatial interpolation was designed for application at continental and global scale and over-emphasizes the elevation and temperature isotope effect simply due to the lack of data. Only one historic GNIP station hosted by the International Atomic and Energy Agency (IAEA/WMO, 2016) could be identified in the south of Scotland. Incomplete data highlights the need for more continuous and spatially distributed precipitation sampling efforts to further develop isoscapes of the hydrological cycle in Scotland similar to the British Isotopes in Rainfall Project (BIRP) by Tyler et al. (2016). While our isotope record is still limited, it can be considered representative of the regional spatial scale of Scotland.

Generally, Scotland's climate is mainly dominated by westerly frontal systems, but spatial and temporal patterns of isotope inputs are potentially influenced by five contrasting air mass types: a) tropical maritime from the sub-tropical north Atlantic Ocean (south-westerly direction: warm moist air with orographic enhancement over the central highlands), b) tropical continental from central and southern Europe (south-easterly direction: dry air in summer), c) polar maritime from Greenland and Arctic Sea (north-west or westerly direction: wet cold air that brings rain showers in winter), d) Arctic maritime (northerly direction: wet cold air that brings snow and rain in winter), and e) polar continental from central/southern Europe and southern Russia (north-east or south easterly direction: cold air that brings snow in winter and dry air in summer) (Mayes and Wheeler, 2013; McClatchey, 2014). The surface air pressure difference from Iceland and the Azores (also known as the North Atlantic Oscillation index, NAO) is a key indicator to determine the scale of weather systems arriving to the west coast (positive mode - stronger than usual subtropical high pressure center) and the north-eastern domain (negative mode deeper than normal Icelandic low) of Scotland. This phenomenon brings enriched moisture from the sub-tropical North Atlantic Ocean 
A

\section{Legend}

- Monitoring

$\delta^{2} \mathrm{H}$ surface water isoscape (\%o)

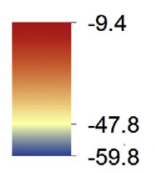

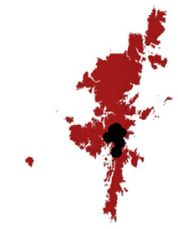

B

\section{Legend}

- Monitoring

d-ex surface water isoscape (\%o)

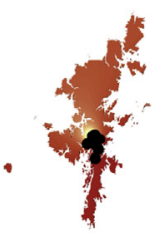

16.8

11 0.72

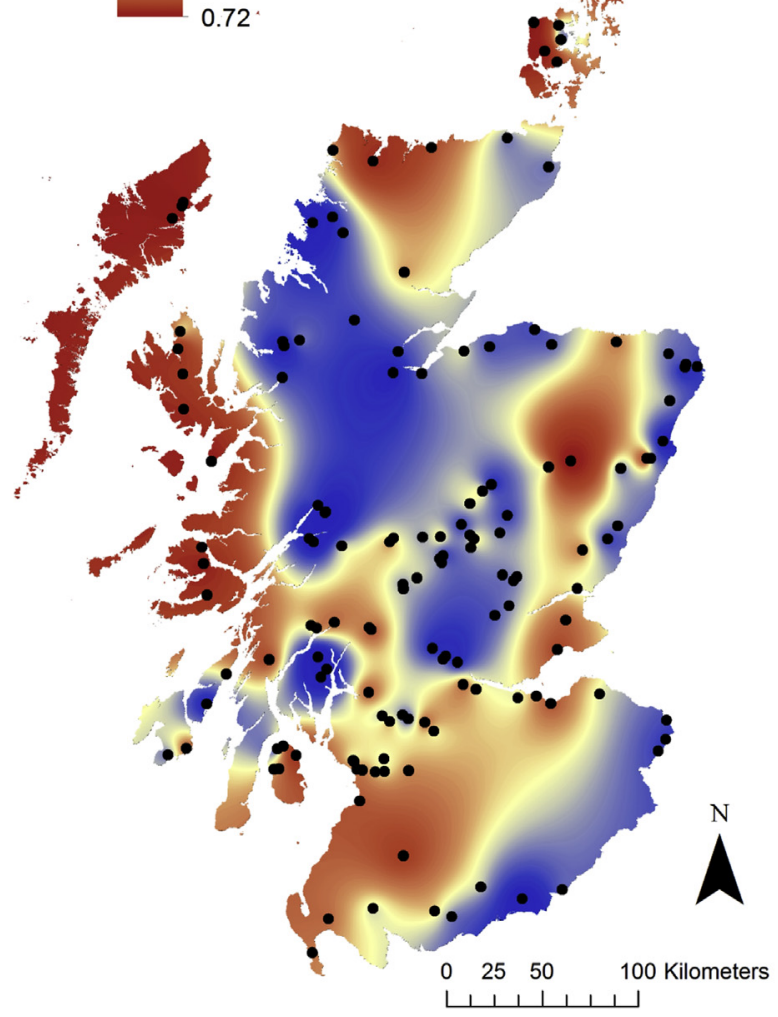

Fig. 3. The map of Scotland includes: A) the Scottish mean $\delta^{2} \mathrm{H}(\%)$ surface water isoscape and B) the mean $d$-excess (\%o) isoscape as a spline interpolated $100 \mathrm{~m}$ grid with corresponding complete surface water isotope monitoring $(n=146)$ for reference (black dots). (For interpretation of the references to colour in this figure, the reader is referred to the web version of this article.)

( $-85 \%$ to $-115 \%$ for $\delta^{2} \mathrm{H}$ in the marine surface layer, Good et al., $2015)$ in comparison to more depleted isotopes towards the North Sea and the Arctic $\left(-115 \%\right.$ to $-135 \%$ for $\delta^{2} \mathrm{H}$ in the marine surface layer, Good et al., 2015). In addition, the existence of a north-south mountainous range enhanced the orographic distillation of the westerly air masses resulting in notable precipitation amounts in the western Highlands $\left(>3000 \mathrm{~mm} \mathrm{yr}^{-1}\right.$ ), whereas the leeward eastern domain receives less, but more isotopically depleted precipitation (600-800 $\mathrm{mm} \mathrm{yr}^{-1}$ ) (Figs. 1B and 4A). Polar continental easterlies, during the winter months, might also bring depleted precipitation, depending upon the travel distance and continental distillation of the air masses arriving along to the east coast of Scotland. The impact of the moisture source on surface waters can be readily derived from the isoscape maps and cluster analysis (Fig. 4) in terms of spatial isotopic patterns such as e.g., the clear isotopic differentiation between east and west Scotland. In fact, Tyler et al. (2016) found from daily rainfall isotope monitoring across the British Isles, a weak correlation between $\delta^{18} \mathrm{O}$ and temperature $(\mathrm{R}=0.37)$, suggesting that the progressive rainout effect from west to east (i.e., westerlies) in Scotland (Fig. 3A) and from north to south over the whole region, and the contrasting moisture source origin, are the key parameters when analyzing the spatial variability of stable isotope composition in the British Isles. For instance, in northern Britain, $\delta^{18} \mathrm{O}$ in precipitation is more sensitive to the rainout effect, whereas in low elevation sites, isotopes are more sensitive to changes in moisture origin and temperature. A recent groundwater isoscape for Ireland by Regan et al. (2017) showed a similar west-east gradient with decreasing isotope values mainly due to similar moisture sources from the west and rain-out effects of heavier isotopes.

\subsection{Modelling of surface water stable isotopes and important drivers}

The GWR $\delta^{2} \mathrm{H}$ model did not identify any hydro-climatic variables based on the AICc and adjR $R^{2}$ model selection criteria whilst the catchment characteristics such as land cover (forest), standard percentage runoff from soils (SPR), catchment area, and elevation were the more important explanatory variables that exert a control on surface water isotopes. In contrast, Wassenaar et al. (2009) have found mean annual precipitation to be significantly related to explain a $\delta^{2} \mathrm{H}$ groundwater isoscape for Mexico whereby groundwaters are mostly recharged by intense precipitation events that do not undergo fractionation (Jasechko and Taylor, 2015).

Our relatively parsimonious 4 parameter model (Table 2) reproduced most spatial patterns such as the isotopic orographic separation, but failed to reproduce the observed surface water isotopes in the south-western region (Fig. 5). Since $\delta^{2} \mathrm{H}$ and $\delta^{18} \mathrm{O}$ isoscapes are 


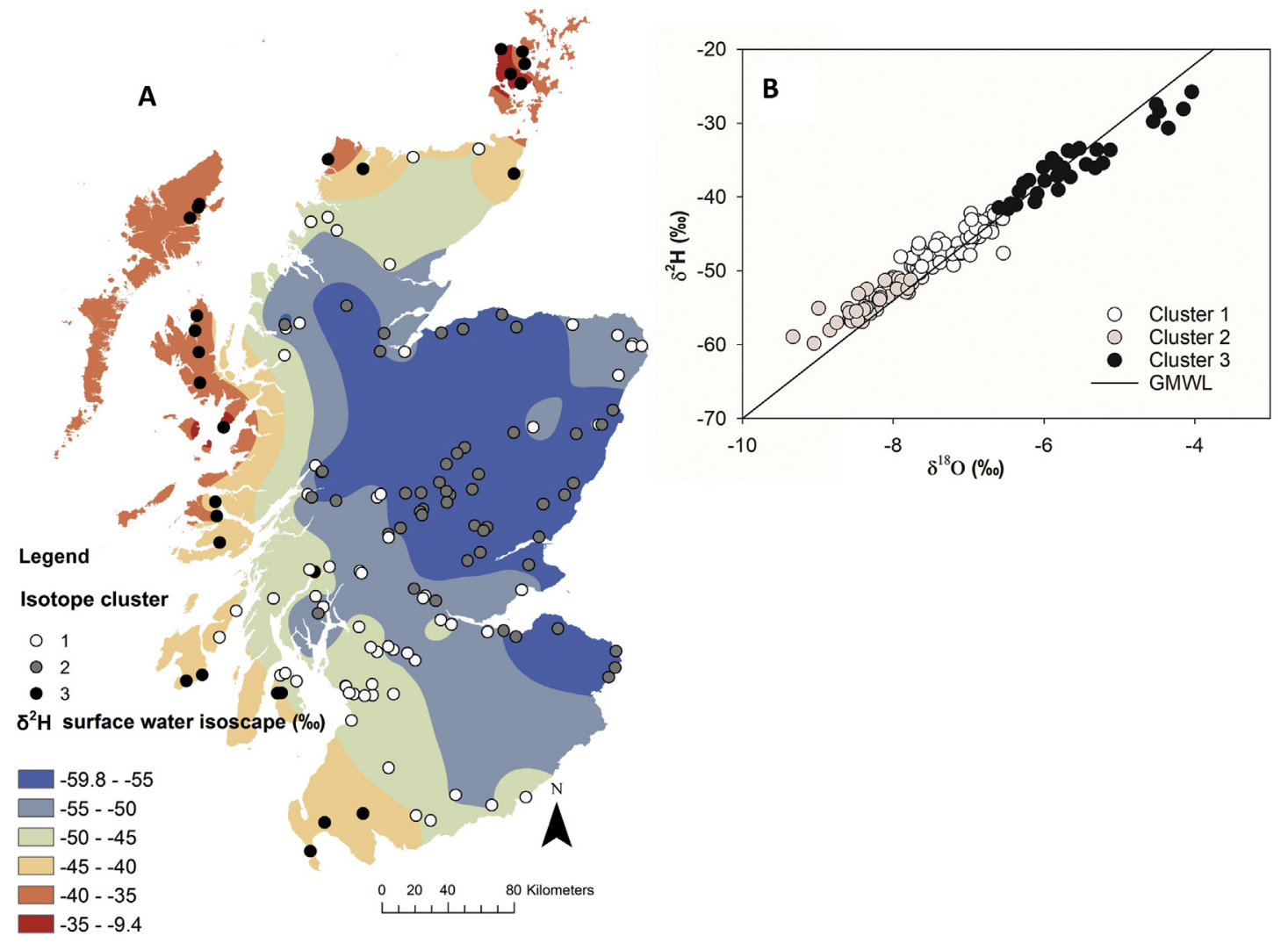

Fig. 4. A) The reclassified surface water $\delta^{2} \mathrm{H}(\%)$ isoscape from Fig. $3 \mathrm{~A}$ is shown as a base map and compared to the isotope clusters (1-white, 2-grey and 3-black) reflecting similar $\delta^{2} \mathrm{H}$ and $\delta^{18} \mathrm{O}$ signatures. B) The calculated isotope clusters are plotted against the Global Meteoric Water Line (GMWL) with cluster 3 reflecting the most enriched group covering the northern and western Islands and the west coast of Scotland. The cluster 2 reflects the most depleted group with catchments draining the Central Highlands and towards the east coast. The cluster 1 lies isotopically and spatially in between.

highly correlated $(R=0.96)$, this resulted in the selection of the same GWR model. Elevation as an explanatory variable does have a physical meaning in terms of the well-known isotope elevation effect (Gat, 1996). The catchment area that drains towards the sampling site represents a myriad of processes related to soil, vegetation, and groundwater characteristics. The latter variables were also independently selected to inform the final GWR $\delta^{2} \mathrm{H}$ model. Land cover provides some physical interpretation of isotope patterns since urban cover is likely to enhance evaporation and associated fractionation. Therefore, urban cover can explain more enriched isotopic signatures, whereas increased forest cover and low SPR values can be linked to more depleted signatures due to a potentially increased infiltration and less superficial soil evaporation (increased plant transpiration is usually not associated with fractionation). However, the latter reasoning is based on the large scale GWR models and might not hold at small catchment scales similar to Geris et al. (2015). Such scale issues further emphasize the need for detailed monitoring and data collection efforts.

This type of GWR model can also be used to assess how isotopes are likely to respond to various drivers of change in the future. For example, a 10\% decrease in forest cover (all other variables being assumed constant) resulted, on average, in a $1.2 \%$ decrease of predicted surface water $\delta^{2} \mathrm{H}$. Increased forest cover resulted in more depleted values mainly due to higher infiltration. Less forest cover was linked to more enriched simulations associated to larger scale superficial water prone to evaporation. Similarly, a $10 \%$ change in the AET/MAP index, according to a projected increased and/or decreased annual precipitation, resulted in an on average $0.8 \%$ change in simulated $d$-excess. This type of analysis will be pursued in more detail in the near future as the GWR models can potentially be applied to a scenario analysis that takes spatial variability of e.g. forest cover changes into account.

The selected best-fit and most parsimonious $d$-excess GWR model was less successful (4 parameters, Table 2), but did, in comparison to the GWR $\delta^{2} \mathrm{H}$ model, take hydro-climatic variables (AET/MAP index) into account. This could be explained by the fact that stable isotope composition in surface waters are ultimately altered due to secondary evaporation processes affecting wetlands and lakes connected to the stream network, whereas $d$-excess is more sensitive to the overall regional climatic conditions at the moisture source.

Both the spline and GWR interpolations represent the major isotopic separation from east to west and north to south. Both algorithms are generally comparable, even though there are smaller scale differences and both models performed better in simulating the west coast compared to the more variable east coast. Also, both models failed to simulate the isotopic pattern observed for the south-western region of Scotland (Fig. 5 and 6), which could be related to different and varying land use management and temperature (more pasture and a milder climate). We, therefore, cannot exclude other potentially simpler and more parsimonious models, that aim to compare the most widely applied interpolation technique (spline) to a spatially non-stationary method (GWR). The failure of these regression models might be related to the interpolation errors of both algorithms particularly at edges and the fact that small scale land use changes affect the isotope signatures (which can only be resolved with higher resolution sampling efforts). Key contributing factors may include larger distances to observations, co-linearity and the selection of regression coefficients (Wheeler and Calder, 2007) and unaccounted atmospheric water vapour transport and circulation patterns that mix the original isotopic source signal, and small scale evaporative fractionation mainly related to the connection of flow pathways (Noone and Simmonds, 2002; Birks and Edwards, 2009). 


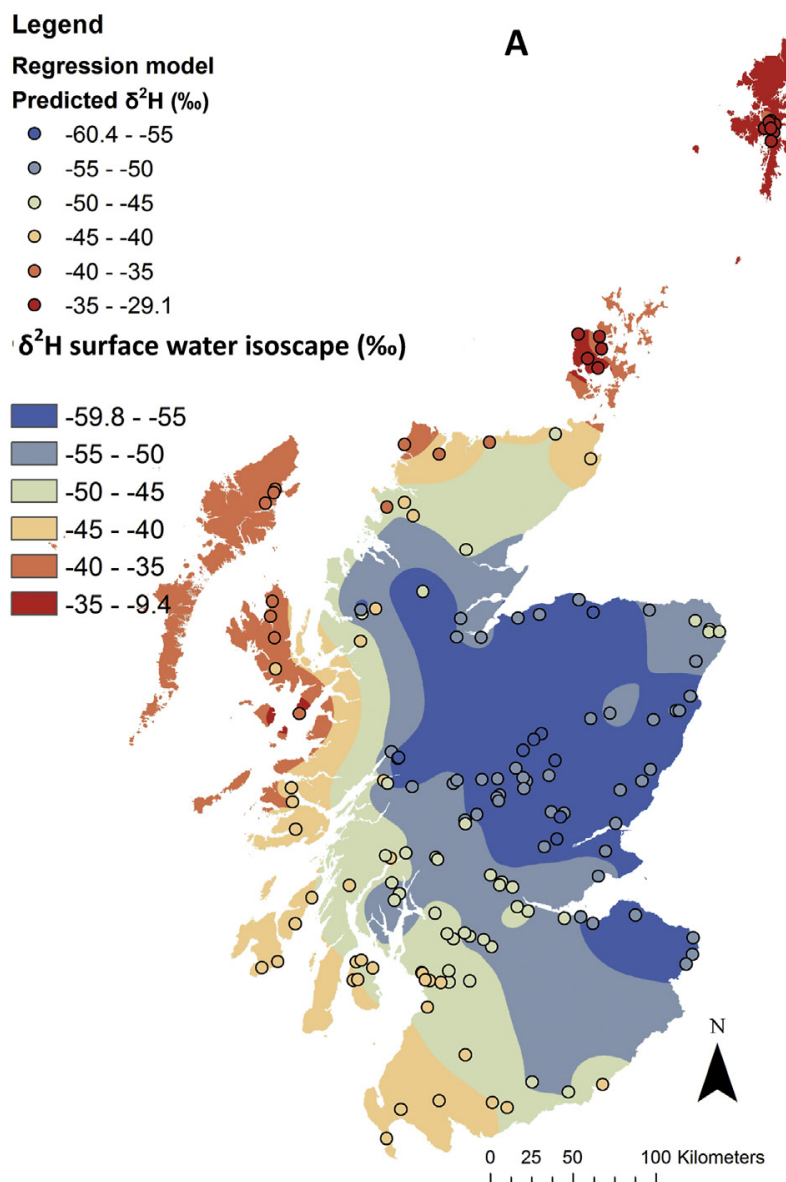
Legend
Regression model
Local $^{2}(-)$
- $0.12-0.2$
○ $0.2-0.3$
$0.3-0.4$
○ $0.4-0.5$
- $0.5-0.63$

$\delta^{2} \mathrm{H}$ surface water isoscape (\%o)

B

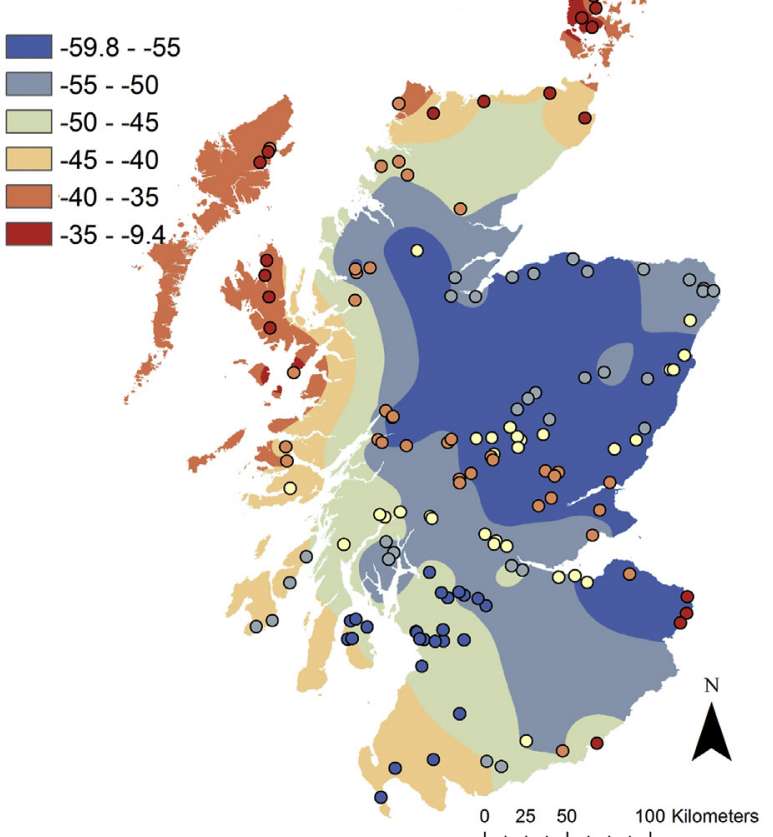

Fig. 5. A) The reclassified surface water $\delta^{2} \mathrm{H}(\%)$ interpolation from Fig. $3 \mathrm{~A}$ is shown as a base map and compared to the best-fit GWR model (Table 2) using explanatory variables to predict the mean $\delta^{2} \mathrm{H}(\%)$ values. The latter predicted values from this regression model are shown for the same classification and colour codes of the dots facilitate direct comparison. B) The local coefficients of determination $\mathrm{R}^{2}$ are shown in $\mathrm{B}$ ). The best-fit and most parsimonious model (as determined by AICc model comparison from 1 to 11 explanatory variables) resulted in an adjR ${ }^{2}=0.66$ and used catchment area, forest cover, urban cover, SPR, and mean catchment elevation as explanatory variables. All selected variables were significant at $\mathrm{p}<0.01$ and resulted in a VIF $<2.6$. (For interpretation of the references to colour in this figure legend, the reader is referred to the web version of this article.)

\section{Conclusions}

We complemented the combined two-year University of Aberdeen and NWIS data $(n=90)$ with a low flow sampling campaign for isotope analysis $(n=56)$ across the under-represented west and northern region of Scotland. Here we developed for the first time, national-scale surface water isoscape maps and a comprehensive assessment of drivers. Subsequently, we showed the spatial distribution of mainly surface water isotopes and derived $d$-excess across Scotland in the form of high spatial resolution $(100 \mathrm{~m})$ isoscapes. The spline interpolated isoscapes were analysed using GWR models to assess spatial patterns, important drivers on surface water isotopes and their relationship to parental moisture sources. Additionally, the NWIS monitoring allowed an evaluation of seasonal effects on surface water isotopes, which were also compared in the context of fewer and spatially concentrated (east coast) precipitation and groundwater isotope monitoring sites. The key outcomes from this research include:

- Strong isotopic gradients from west to east.

- Precipitation isotope patterns can be inferred from surface water isoscapes and synoptic weather patterns related to moisture origin.

- Despite energy limitation, we observed evaporative fractionation effects in surface waters.

- Deuterium excess indicated an influence of mixed and contrasting

Table 2

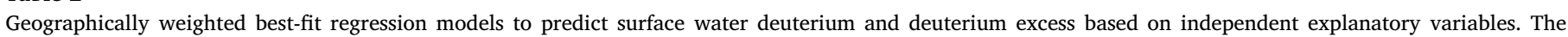
coefficients are given as spatially mean values \pm standard deviation and [range].

\begin{tabular}{|c|c|c|c|c|c|c|c|c|}
\hline $\begin{array}{l}\text { Dependent } \\
\text { variable }\end{array}$ & Intercept & Area & SPR & Forest & Elevation & Residuals & AICc & $\operatorname{adj}^{2}$ \\
\hline$\delta^{2} \mathrm{H}(\% 0)$ & $\begin{array}{l}-48.1 \pm 7.3 \\
{[-63.2,-30.5]}\end{array}$ & $\begin{array}{l}-0.003 \pm 0.002 \\
{[-0.008,-0.0006]}\end{array}$ & $\begin{array}{l}0.06 \pm 0.12[-0.12 \\
-0.51]\end{array}$ & $\begin{array}{l}-0.04 \pm 0.28 \\
{[-0.93,0.28]}\end{array}$ & $\begin{array}{l}-0.017 \pm 0.009 \\
{[-0.04,-0.004]}\end{array}$ & $\begin{array}{l}0.49 \pm 2.85 \\
{[-4.3,5.7]}\end{array}$ & 876 & 0.75 \\
\hline $\begin{array}{l}\text { Dependent } \\
\text { variable }\end{array}$ & Intercept & AET/MAP & Area & Urban & Elevation & Residuals & AICc & $\operatorname{adj}^{2}$ \\
\hline$d$-Excess $(\% 0)$ & $\begin{array}{l}10.67 \pm 1.5[5.04, \\
11.7]\end{array}$ & $\begin{array}{l}0.24 \pm 2.53[0.01, \\
10.9]\end{array}$ & $\begin{array}{l}0.0005 \pm 0.0004 \\
{[0.00009,0.0023]}\end{array}$ & $\begin{array}{l}-0.11 \pm 0.19 \\
{[-0.82,-0.09]}\end{array}$ & $\begin{array}{l}0.0024 \pm 0.0034 \\
{[-0.0064,0.0096]}\end{array}$ & $\begin{array}{l}-0.1 \pm 1.9 \\
{[-2.6,3.9]}\end{array}$ & 644 & 0.32 \\
\hline
\end{tabular}




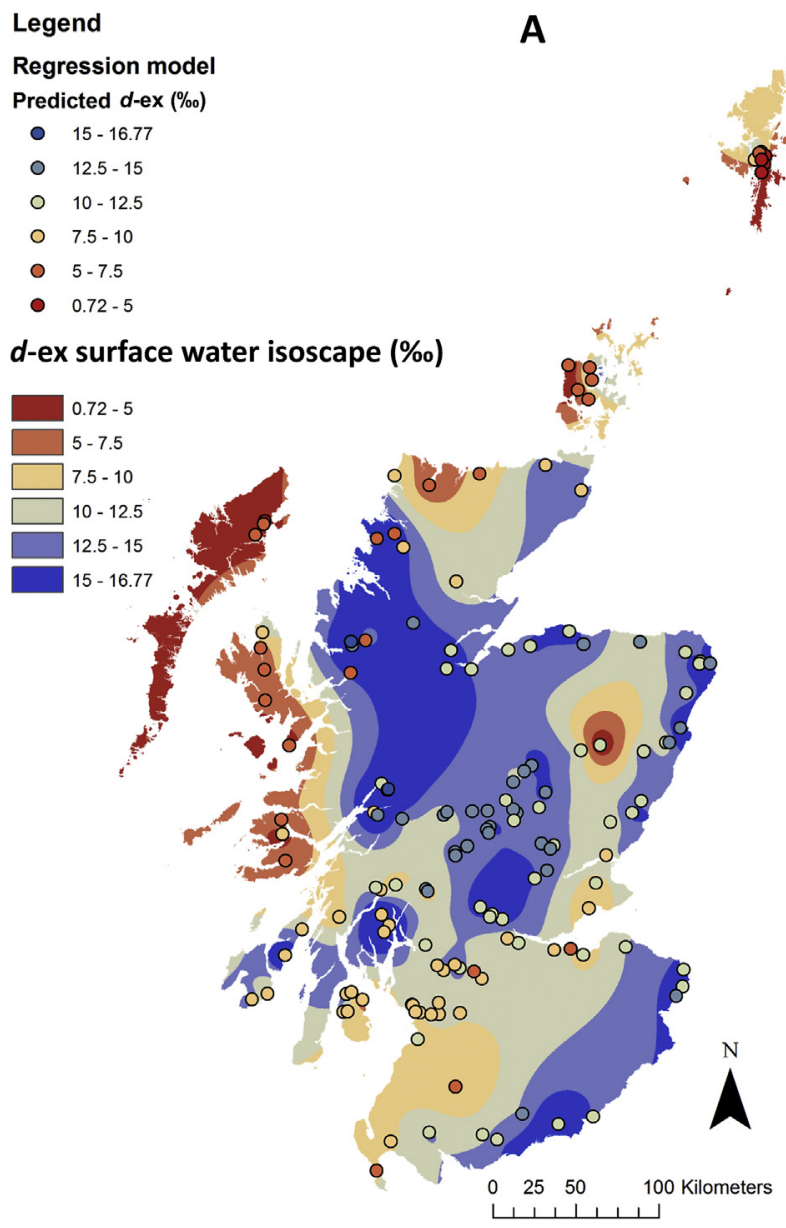
Legend
Regression model
LocalR $^{2}(-)$
- $0.25-0.38$
○ $0.17-0.24$
○ $0.12-0.16$
○ $0.09-0.11$
○ $0.06-0.08$
- $0.03-0.05$

\section{d-ex surface water isoscape (\%o)}

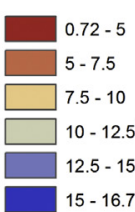

B

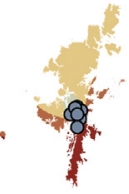

Fig. 6. A) The reclassified surface water $d$-excess (\%) interpolation from Fig. 3B is shown as a base map and compared to the best-fit GWR model (Table 2) using explanatory variables to predict the mean $d$-excess values (\%). The latter predicted values from this regression model are shown for the same classification and colour codes facilitating direct comparison. B) The local coefficients of determination $\mathrm{R}^{2}$ are shown in $\mathrm{B}$ ). The best-fit and most parsimonious model (as determined by AICc model comparison from 1 to 11 explanatory variables) resulted in an adj $\mathrm{R}^{2}=0.35$ and used AET/MAP, urban cover, catchment area, and mean catchment elevation as explanatory variables. All selected variables were significant at $\mathrm{p}<0.01$ and resulted in a VIF $<1.9$. (For interpretation of the references to colour in this figure legend, the reader is referred to the web version of this article.)

oceanic moisture sources in combination with an important contribution of more locally and continentally recycled moisture.

- GWR modelling is a useful tool to assess spatial patterns and identify spatial drivers of surface water isotopes.

- Seasonal LELs of surface waters suggested a progressive evaporative enrichment from spring to autumn.

- Isoscapes provide baseline data for hydrologic, ecologic, forensic, paleoclimate, and archaeological studies.

In addition to static catchment characteristics, the GWR models identified dynamic variables that are subject to change such as land cover and hydro-climatic variables. We, therefore, conclude that these models could be used in preliminarily assessments of past and future isotopic changes that relate to changing moisture sources and catchment characteristics.

Supplementary data to this article can be found online at https:// doi.org/10.1016/j.gexplo.2018.07.011.

\section{Acknowledgements}

This paper was partly funded by the Rural \& Environment Science \& Analytical Services Division of the Scottish Government. CB acknowledges support from the University of Costa Rica Research Council (project 217-B4-239). CS, DT, RSM, GEH and CB participated under the University of Costa Rica Research Council funded Isotope Network for
Tropical Ecosystem Studies (ISONet). RSM acknowledges the support from the International Atomic Energy Agency (grant CRP-19747). DT and CS acknowledge funding from the European Research Council ERC (project GA 335910 VEWA) and the Natural Environment Research Council NERC (project NE/K000268/1). We thank Dr. Sarah Dunn and the late Dr. Julian Dawson for their help and encouragement in the initiation of this project. We thank all who provided samples for the low flow spot sampling scheme. Comments from Mark Brewer and two anonymous Reviewers improved the quality of the final paper. All $100 \mathrm{~m}$ isoscape raster maps and isotope data are available for download.

\section{References}

Birkel, C., Soulsby, C., Ali, G., Tetzlaff, D., 2013. Assessing the cumulative impacts of hydropower regulation on flow characteristics in a large Atlantic Salmon river system. River Res. Appl. https://doi.org/10.1002/rra.2656.

Birks, S.J., Edwards, T.W.D., 2009. Atmospheric circulation controls on precipitation isotope-climate relations in western Canada. Tellus Ser. B. 61, 566-576.

Boorman, D.B., Hollis, J.M., Lilly, A., 1995. Hydrology of Soil Types: A Hydrologically Based Classification of the Soils of the United Kingdom. Institute of Hydrology Report No. 126. (137pp).

Bowen, G.J., Good, S.P., 2015. Incorporating water isoscapes in hydrological and water resource investigations. Wiley Interdiscip. Rev. Water 2 (2), 107-119. https://doi. org/10.1002/wat2.1069.

Bowen, G.J., Revenaugh, J., 2003. Interpolating the isotopic composition of modern meteoric precipitation. Water Resour. Res. 39, 1299.

Bowen, G.J., Kennedy, C.D., Liu, Z., Stalker, J., 2011. Water balance model for mean 
annual hydrogen and oxygen isotope distributions in surface waters of the contiguous United States. J. Geophys. Res. Biogeosci. 116 (G4).

British Geological Society, 2016. Hydrogeological Maps of Scotland. Cited [07/01/ 2017]. Available from: http://www.bgs.ac.uk/products/hydrogeology/ HydrogeologicalMapsScotland.html.

Brunsdon, C., Fotheringham, A.S., Charlton, M., 1996. Geographically weighted regression - a method for exploring spatial non-stationarity. Geogr. Anal. 28, 281-298.

Dansgaard, W., 1964. Stable isotopes in precipitation. Tellus 16, 436-468. https://doi. org/10.1111/j.2153-3490.1964.tb00181.x.

Darling, W.G., Talbot, J.C., 2003. The O \& H stable isotopic composition of fresh waters in the British Isles. 1, rainfall. Hydrol. Earth Syst. Sci. 7, 163-181.

Dawson, J.J.C., Avery, L.M., Baggaley, N.J., Cooper, P., Kemp, H.F., Meier-Augenstein, W., et al., 2012. A National Waters Inventory for Scotland: new approaches to monitor water quality. In: Conference: BHS 11th National Hydrology Symposium, https://doi.org/10.7558/bhs.2012.ns13.

Evaristo, J., Jasechko, S., McDonnell, J.J., 2015. Global separation of plant transpiration from groundwater and streamflow. Nature 525 (7567), 91-94. https://doi.org/10. 1038/nature14983.

Ferrier, R.C., Edwards, A.C., Hirst, D., Littlewood, I.G., Watts, C.D., Morris, R., 2001. Water quality of Scottish rivers: spatial and temporal trends. Sci. Total Environ. 265, 327-342.

Fotheringham, Stewart A., Brunsdon, Chris, Charlton, Martin, 2002. Geographically Weighted Regression: The Analysis of Spatially Varying Relationships. John Wiley \& Sons.

Franke, R., 1982. Smooth interpolation of scattered data by local thin plate splines. Comp. Math. Appl. 8 (4), 273-281. https://doi.org/10.1016/0898-1221(82)90009-8.

Gat, J.R., 1996. Oxygen and hydrogen isotopes in the hydrologic cycle. Annu. Rev. Earth Planet. Sci. 24, 225-262.

Gat, J.R., Bowser, C.J., Kendall, C., 1994. The contribution of evaporation from the Great Lakes to the continental atmosphere: estimate based on stable isotope data. Geophys. Res. Lett. 21, 557-560.

Geris, J., Tetzlaff, D., McDonnell, J., Anderson, J., Paton, G., Soulsby, C., 2015. Ecohydrological separation in wet, low energy northern environments? A preliminary assessment using different soil water extraction techniques. Hydrol. Process. 29, 5139-5152. https://doi.org/10.1002/hyp.10603.

Good, S.P., Mallia, D.V., Lin, J.C., Bowen, G.J., 2014. Stable isotope analysis of precipitation samples obtained via crowdsourcing reveals the spatiotemporal evolution of superstorm sandy. PLoS One 9 (3), e91117. https://doi.org/10.1371/journal.pone. 0091117.

Good, S.P., Noone, D., Kurita, K., Benetti, M., Bowen, G.J., 2015. D/H isotope ratios in the global hydrologic cycle. Geophys. Res. Lett. 42, 5042-5050. https://doi.org/10. 1002/2015GL064117.

Gupta, P., Noone, D., Galewsky, J., Sweeney, C., Vaughn, B.H., 2009. A new laser-based, field-deployable analyzer for laboratory-class stable isotope measurements in water. Geochim. Cosmochim. Acta 73, A480.

Heilweil, V.M., Solomon, D.K., Gingerich, S.B., Verstraeten, I.M., 2009. Oxygen, hydrogen, and helium isotopes for investigating groundwater systems of the Cape Verde Islands, West Africa. Hydrogeol. J. 17 (5), 1157-1174. https://doi.org/10.1007/ s10040-009-0434-2.

Hurvich, C.M., Tsai, C.L., 1993. A corrected Akaike information criterion for vector autoregressive model selection. J. Time Ser. Anal. 14 (3), 271-279. https://doi.org/10. 1111/j.1467-9892.1993.tb00144.x.

IAEA/WMO, 2016. Global Network of Isotopes in Precipitation and Global Network of Isotopes in River. The GNIP and GNIR Databases. Cited [21/12/2016]. Available from: http://www.iaea.org/water.

Jasechko, S., Taylor, R.G., 2015. Intensive rainfall recharges tropical groundwaters. Environ. Res. Lett. 10 (12), 124015. https://doi.org/10.1088/1748-9326/10/12/ 124015.

Jasechko, S., Sharp, Z.D., Gibson, J., Birks, S.J., Yi, Y., Fawcett, P.J., 2013. Terrestrial water fluxes dominated by transpiration. Nature 496 (7445), 347-350. https://doi. org/10.1038/nature11983.

Jouzel, J., Delaygue, G., Landais, A., Masson-Delmotte, V., Risi, C., Vimeux, F., 2013. Water isotopes as tools to document oceanic sources of precipitation. Water Resour. Res. 49, 7469-7486. https://doi.org/10.1002/2013WR013508.

Kaseke, K.F., Wang, L., Wanke, H., Turewicz, V., Koeniger, P., 2016. An analysis of precipitation isotope distributions across Namibia using historical data. PLoS One 11 (5), e0154598. https://doi.org/10.1371/journal.pone.0154598.

Lachniet, M., 2009. Sea surface temperature control on the stable isotopic composition of rainfall in Panama. Geophys. Res. Lett. 36, L03701. https://doi.org/10.1029/ 2008GL036625.

Lachniet, M., Paterson, W., 2009. Oxygen isotope values of precipitation and surface waters in northern Central America (Belize and Guatemala) are dominated by temperature and amount effects. Earth Planet. Sci. Lett. 284, 435-446. https://doi.org/ 10.1016/j.epsl.2009.05.010.
Mayes, J., Wheeler, D., 2013. Regional weather and climates of the British Isles-part 1: introduction. Weather 68 (1), 3-8. https://doi.org/10.1002/wea.2041.

McClatchey, J., 2014. Regional weather and climates of the British Isles-part 9: Scotland. Weather 69 (10), 275-281. https://doi.org/10.1002/wea.2290.

Met Office, 2016. http://www.metoffice.gov.uk/datapoint/product/climate-averages (last visited 07/01/2017).

Munksgaard, N.C., Zwart, C., Kurita, N., Bass, A., Nott, J., Bird, M.I., 2014. Stable isotope anatomy of tropical cyclone Ita, North-Eastern Australia. PLoS ONE 10 (3), e0119728. https://doi.org/10.1371/journal.pone.0119728.

Newman, B., Tanweer, A., Kurttas, T., 2009. IAEA Standard Operating Procedure for the Liquid-Water Stable Isotope Analyser. http://www.naweb.iaea.org/napc/ih/ documents/other/laser_procedure_rev12.PDF.

Noone, D., Simmonds, I., 2002. Associations between $\mathrm{d}^{18} \mathrm{O}$ of water and climate parameters in a simulation of atmospheric circulation for 1979-95. J. Clim. 15, 3150-3169.

Regan, S., Goodhue, R., Naughton, O., Hynds, P., 2017. Geospatial drivers of the groundwater $\delta^{18} \mathrm{O}$ isoscape in a temperate maritime climate (Republic of Ireland). J. Hydrol. 554, 173-186. https://doi.org/10.1016/j.jhydrol.2017.09.017.

Risi, C., Bony, S., Vimeux, F., Jouzel, J., 2010. Water-stable isotopes in the LMDZ4 general circulation model: model evaluation for present-day and past climates and applications to climatic interpretations of tropical isotopic records. Geophys. Res. Atmos. 115 (D12). https://doi.org/10.1029/2009JD013255.

R, Sanchez-Murillo, C, Birkel, 2016. Groundwater recharge mechanisms inferred from isoscapes in a complex tropical mountainous region. Geophys. Res. Lett. 1-10. https://doi.org/10.1002/2016GL068888.

Sánchez-Murillo, R., Birkel, C., Welsh, K., Esquivel-Hernández, G., Corrales-Salazar, J., Boll, J., Brooks, E., et al., 2016a. Key drivers controlling stable isotope variations in daily precipitation of Costa Rica: Caribbean Sea versus Eastern Pacific Ocean moisture sources. Quat. Sci. Rev. 131 (Part B), 250-261. https://doi.org/10.1016/j. quascirev.2015.08.028.

Sánchez-Murillo, R., Durán-Quesada, A.M., Birkel, C., Esquivel-Hernández, G., Boll, J., 2016b. Tropical precipitation anomalies and d-excess evolution during El Niño 2014-16. Hydrol. Process. https://doi.org/10.1002/hyp.11088.

Soulsby, C., Tetzlaff, D., Rodgers, P., Dunn, S., Waldron, S., 2006. Runoff processes, streamwater residence times and controlling landscape characteristics in a mesoscale catchment: an initial assessment. J. Hydrol. 325, 197-221.

Soulsby, C., Birkel, C., Geris, J., Tetzlaff, D., 2014. The isotope hydrology of a large regulated river system. River Res. Appl. https://doi.org/10.1002/rra.2740.

Soulsby, C., Birkel, C., Geris, J., Dick, J., Tunelay, C., Tetzlaff, D., 2015. Stream water age distributions controlled by storage dynamics and non-linear connectivity between landscape units. Water Resour. Res. https://doi.org/10.1002/2015WR017888.

Spezia, L., Brewer, M.J., Birkel, C., 2017. An anisotropic and inhomogeneous hidden Markov model for the classification of water quality spatio-temporal series. Environmetrics 28, e2427. https://doi.org/10.1002/env.2427.

Sprenger, M., Tetzlaff, D., Tunaley, C., Dick, J., Soulsby, C., 2016. Evaporation fractionation in a peatland drainage network affects stream water isotope composition. Water Resour. Res. https://doi.org/10.1002/2016WR019258.

Terzer, S., Wassenaar, L.I., Araguás-Araguás, L.J., Aggarwal, P.K., 2013. Global isoscapes for $\delta^{18} \mathrm{O}$ and $\delta^{2} \mathrm{H}$ in precipitation: improved prediction using regionalized climatic regression models. Hydrol. Earth Syst. Sci. 17 (11), 4713-4728. https://doi.org/10. 5194/hess-17-4713-2013.

Tyler, et al., 2016. Spatial patterns in the oxygen isotope composition of daily rainfall in the British Isles. Clim. Dyn. 47, 1971-1987.

Vimeux, F., Gallaire, R., Bony, S., Hoffmann, G., Chiang, J.C.H., 2005. What are the climate controls on $\mathrm{dD}$ in precipitation in the Zongo Valley (Bolivia)? Implications for the Illimani ice core interpretation. Earth Planet. Sci. Lett. 240, 205-220. https://doi. org/10.1016/j.epsl.2005.09.031.

Wassenaar, L.I., Van Wilgenburg, S.L., Larson, K., Hobson, K.A., 2009. A groundwater isoscape $\left(\delta \mathrm{D}, \delta^{18} \mathrm{O}\right)$ for Mexico. J. Geochem. Explor. 102 (3), 123-136. https://doi. org/10.1016/j.gexplo.2009.01.001.

West, J.B., Bowen, G.J., Dawson, T.E., Tu, K.P., 2010. Isoscapes: Understanding Movement, Pattern, and Process on Earth Through Isotope Mapping. Springer, The Netherlands. https://doi.org/10.1007/978-90-481-3354-3.

Wheeler, D., Calder, C., 2007. An assessment of coefficient accuracy in linear regression models with spatially varying coefficients. J. Geogr. Syst. 9, 145-166.

Yamanaka, T., Makino, Y., Wakiyama, Y., Kishi, K., Maruyama, K., Kano, M., Ma, W., Suzuki, K., 2015. How reliable are modeled precipitation isoscapes over a high-relief mountainous region? Hydrol. Res. Lett. 9 (4), 118-124. https://doi.org/10.3178/hrl. 9.118

Zhang, K., Kimball, J.S., Mu, Q., Jones, L.A., Goetz, S.J., Running, S.W., 2009. Satellite based analysis of northern ET trends and associated changes in the regional water balance from 1983 to 2005. J. Hydrol. 379, 92-110. https://doi.org/10.1016/j. jhydrol.2009.09.047. 